\title{
Espacialização de áreas inundáveis no baixo curso do Rio Tibagi - PR
}

\section{Flooded areas spatialization in the lower course of the Tibagi River, Paraná state, Brazil}

\author{
Rodrigo Vitor Barbosa Sousa ${ }^{1 *} \bowtie$ iD, Paulo Cesar Rocha ${ }^{\star} \varangle$ (iD \\ Centro Estadual de Educação Tecnológica Paula Souza, São Paulo, Brasil \\ Departamento de Geografia, Faculdade de Ciências e Tecnologia, Universidade Estadual \\ Paulista "Júlio de Mesquita Filho", Presidente Prudente, Brasil \\ E-mail: pcrocha@fct.unesp.br \\ *E-mail para correspondência: rorvbs@gmail.com
}

\author{
Recebido (Received): 24/02/2020
}

Aceito (Accepted):16/03/2020

\begin{abstract}
Resumo: Esse artigo teve como objetivo espacializar as áreas inundáveis no sítio urbano de Jataizinho - PR, que fica no baixo curso do Rio Tibagi e é considerada uma das cidades mais afetadas pelas inundações desse rio. O mapeamento foi realizado por meio do uso de geotecnologias, como GNSS, estereoscopia digital e geoprocessamento. Os resultados apontam que as inundações estão concentradas em dois grupos principais, quais sejam, grupo A: inundações nas áreas de planície fluvial e na transição destas com áreas de terraço, compreendidas entre as cotas altimétricas $339,346 \mathrm{~m}$ e $340,520 \mathrm{~m}$; e grupo B: inundações nas áreas de terraço e na transição destas com algumas colinas, ou seja, entre as cotas altimétricas 340,521 m e 341,59 m. As inundações do Rio Tibagi apresentam período de retorno a partir de 5 anos, já os episódios mais bruscos de inundações denotam período de retorno a partir de 25 anos. Observa-se que, parte significativa das áreas inundáveis é ocupada por habitantes da cidade. Os resultados obtidos mostraram-se satisfatórios, de modo que o mapeamento realizado poderá ser utilizado como ferramenta de apoio ao ordenamento territorial e ambiental da cidade de Jataizinho.
\end{abstract}

Palavras-chave: Inundação; Geotecnologia; Mapeamento.

Abstract: The aim of this paper was to spatialize the flooded areas in the urban site of Jataizinho, Parana State, Brazil, which is located in the lower course of the Tibagi River and is considered one of the most affected cities by the river floods. The mapping was performed with the use of geotechnologies, such as GNSS, digital stereoscopy and geoprocessing. The results indicate that the floods are concentrated in two main groups, namely, group A: floods in the floodplain areas and their transition to terraced areas, ranging from 339,366 $m$ to 340,520 m altitude; and group B: floods in the terraced areas and their transition with some areas of hills, i.e., between altitudes 340,521 m and 341,59 m. The Tibagi River floods have a return period of 5 years, while the most abrupt episodes of flood denote return period of 25 years. It is possible to observe that city inhabitants occupy a significant part of the flooded areas. The results were satisfactory, meaning that the mapping can be used as a tool to support the territorial and environmental planning of the city of Jataizinho.

Keywords: Flood; Geotechnology; Mapping.

\section{Introdução}

Não é raro encontrar na literatura geográfica e de áreas correlatas trabalhos que tratem de problemas relacionados ao fenômeno de inundação. O mapeamento realizado por BRASIL (2015a; 2015b), aponta que a cidade de Jataizinho, localizada no baixo curso do Rio Tibagi - PR, possui alta vulnerabilidade a inundações. Destacam-se os eventos de inundações graduais ou de planície, os quais possuem, como característica principal, a subida e a descida paulatina da cota fluviométrica dos rios. 
Sendo a inundação uma condição existente quando a vazão de um rio não pode ser canalizada dentro de seu canal normal, Christofoletti (1980) faz uma distinção entre os tipos de leitos fluviais, que correspondem aos espaços a serem ocupados pelo escoamento das águas. Assim, quanto ao perfil transversal nas planícies de inundação, podem-se distinguir os seguintes tipos de leitos fluviais: a) leito de vazante; b) leito menor; c) leito maior periódico ou sazonal; d) leito maior excepcional. Todavia, na prática, essas delimitações são difíceis de ser traçadas, havendo nitidez maior entre o leito menor e o leito maior.

Conforme Christofoletti (1980), a forma do canal fluvial reflete o ajustamento deste às vazões que fluem através de determinada seção transversal. Ao se considerar que os canais fluviais aluviais resultam da ação que o fluxo exerce sobre os materiais rochosos que compõem o leito e as margens, pode-se dizer que as dimensões deste canal são controladas pelo equilíbrio entre as forças erosivas de entalhamento e os processos agradacionais que depositam material no leito e nas margens. Nesse sentido, o débito de margens plenas bankfull discharge - assume grande importância geomorfológica, uma vez que é definido como a vazão que preenche, na medida justa, o canal fluvial, sendo que acima desta vazão verifica-se o transbordamento para a planície de inundação.

Pode-se dizer que pesquisas com o intuito de espacializar áreas inundáveis e comportamentos hidrológicos em bacias hidrográficas foram fortemente beneficiadas pelas técnicas de geoprocessamento e pelas geotecnologias, na medida em que estas impulsionaram a criação de cenários e modelagens hidrológicas. Assim, muitos são os autores que realizam discussão teórica ou que propõem metodologias para estudos hidrológicos, como o monitoramento e o mapeamento de áreas inundáveis por meio do uso diversificado de geotecnologias, tais quais: GNSS, construção de Modelo Digital de Elevação (MDE) e de Modelo Digital do Terreno (MDT), aerofotogrametria, criação de ortofotos com alta resolução espacial, técnicas a laser como Light Detection And Ranging (LiDAR) e técnicas de sensoriamento remoto orbital. Entre esses autores, podem-se citar os trabalhos de Luedeling et al. (2007), Valeriano (2004, 2006 e 2008), Molina et al. (2014), Zazo et al. (2015), Neal et al. (2009), Lane et al (2003), Aicardi et al. (2015), Pinto et al. (1985), Novo e Santos (1982), Maio (1980) e Sousa, Barros e Pereira Neto (2012).

Conforme França (2002), a cidade de Jataizinho é uma das mais afetadas pelas inundações do Rio Tibagi. O objetivo desse artigo foi, portanto, espacializar as áreas inundáveis na cidade de Jataizinho, mobilizando dados altimétricos e formas de relevo existentes obtidos com o uso de geotecnologias e técnicas de geoprocessamento. A justificativa para o desenvolvimento dessa pesquisa reside na obtenção de detalhamento das áreas sujeitas a inundações para produção de material cartográfico que subsidie tomadas de decisões pelo poder público quanto aos fenômenos de inundações.

A área de estudo está localizada no curso inferior do Rio Tibagi, que, com aproximadamente $550 \mathrm{~km}$ de extensão e inserido em uma bacia hidrográfica com $24.712 \mathrm{Km}^{2}$ de área de drenagem, é considerado o principal tributário da margem esquerda do Rio Paranapanema. Ambos os rios são constituintes da bacia hidrográfica do Rio Paraná (MAACK, 1981; FRANÇA, 2002). A localização da área de estudo pode ser evidenciada na (Figura 1).

Acerca das médias históricas de vazão do Rio Tibagi referentes à estação fluviométrica Jataizinho 64507000, Sousa (2017), com base em uma série de 1932 a 2009, calculou os seguintes valores para as vazões médias, médias das máximas e médias das mínimas: $367 \mathrm{~m}^{3} \mathrm{~s}^{-1}, 805 \mathrm{~m}^{3} \mathrm{~s}^{-1}$ e $206 \mathrm{~m}^{3} \mathrm{~s}^{-1}$. Para as médias, médias das máximas e médias das mínimas das cotas fluviométricas, os valores foram calculados em $206 \mathrm{~cm}, 262 \mathrm{~cm}$ e $164 \mathrm{~cm}$. Vale destacar que o padrão de drenagem da bacia hidrográfica do Tibagi é do tipo paralelo, decorrente, entre outros fatores, dos controles estruturais existentes na área.

Possuindo um clima regional do tipo subtropical, cuja principal massa de ar atuante é a massa tropical atlântica $(\mathrm{mTa})$ - seguida da massa polar atlântica $(\mathrm{mPa})$-; as médias pluviométricas no alto, médio e baixo curso do Rio Tibagi são, respectivamente, $1550 \mathrm{~mm}, 1700 \mathrm{~mm}$ e $1600 \mathrm{~mm}$. Localizada no baixo curso do Rio Tibagi, Norte do Paraná, a área onde o sítio urbano de Jataizinho está situado é reconhecida como área de transição climática (MENDONÇA, 1994, 2002; MONTEIRO, 1962, 1968). 


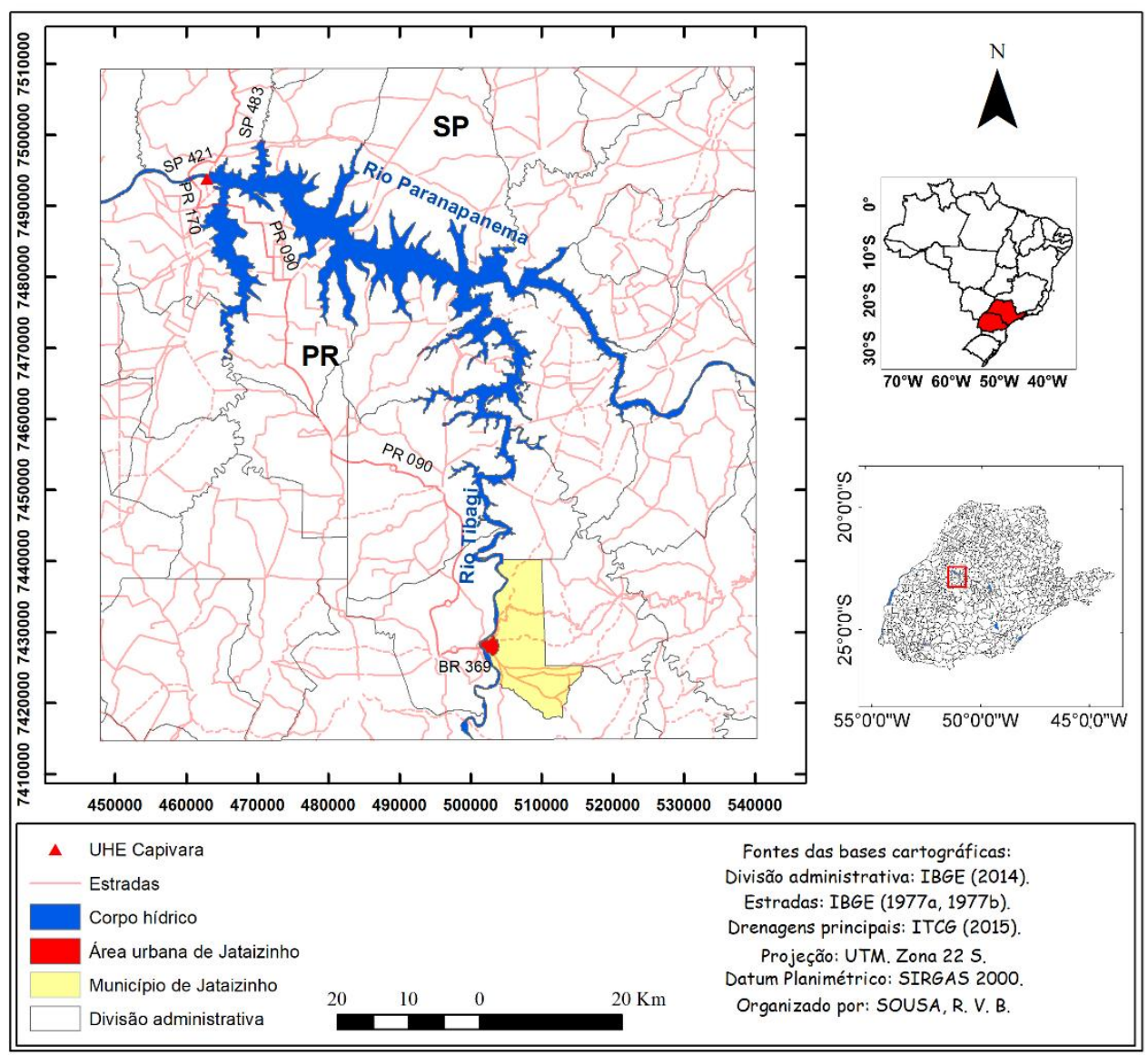

Figura 1: Localização da área de estudo. Organizado por SOUSA, R.V.B.

\section{Materiais e métodos.}

A espacialização das áreas que são inundadas no sítio urbano de Jataizinho foi realizada por meio das seguintes etapas: a) determinação da cota zero do primeiro lance de régua linimétrica da estação fluviométrica Jataizinho - 64507000 por meio de técnicas GNSS; b) identificação da maior cota altimétrica do Rio Tibagi registrada nos dados hidrológicos; c) identificação do nível de margens plenas do Rio Tibagi e identificação das altitudes ortométricas em pontos amostrais do relevo com o uso de estereoscopia digital; d) interpolação dos pontos amostrais de altitude ortométrica do relevo por meio de técnicas de geoprocessamento; e) sobreposição dos dados vetorizados e interpolados sobre formas de relevo já mapeadas para a área de estudo e sobre imagens orbitais de alta resolução espacial.

Nesse sentido, a técnica GNSS empregada foi a relativa estática rápida pós-processada apresentada em Monico (2008). A fim de aumentar a produtividade em campo, o tempo de coleta das coordenadas geodésicas in situ foi de 10 minutos. Os dados foram pós-processados através do software GNSS Solutions. O datum planimétrico utilizado foi o SIRGAS 2000, de modo que a altitude elipsoidal também foi obtida com base neste datum. A projeção adotada foi a Universal Transversa de Mercator - UTM. A altitude geométrica elipsoidal foi convertida para altitude ortométrica - em relação ao geoide ou ao nível médio dos mares - por meio de um modelo de ondulação geoidal para o território brasileiro. Para isso, fez-se uso do software MAPGEO 2010, disponível em IBGE (2015).

Para a determinação da cota zero do primeiro lance de régua linimétrica da estação fluviométrica Jataizinho - 64507000, subtraiu-se o valor da altitude da referência de nível (RN), obtida por técnicas GNSS, pela altura da $\mathrm{RN}$ - marco materializado.

A determinação da cota zero do primeiro lance de régua linimétrica por meio de técnicas GNSS permitiu converter os dados de cota fluviométrica do Rio Tibagi $(\mathrm{cm})$ para cota altimétrica $(\mathrm{m})$. Os dados hidrológicos originais foram obtidos junto ao portal Hidroweb, gerenciado pela Agência Nacional de Águas - ANA (2005), à Superintendência de Gestão de Rede Hidrometeorológica da ANA - SGH/ANA e ao Instituto de Águas do Paraná. A conversão da cota fluviométrica para cota altimétrica possibilitou identificar a maior cota altimétrica do Rio Tibagi já registrada, adotando esse dado como valor máximo para a espacialização do transbordamento do Rio Tibagi. 
Técnicas de estereoscopia digital foram aplicadas para a identificação do nível de margens plenas do Rio Tibagi e para a identificação das altitudes ortométricas em pontos amostrais do relevo. $\mathrm{O}$ modelo estereoscópico foi construído com o software Prestitui.exe, elaborado por Hasegawa (2010). Os produtos de sensoriamento remoto utilizados para a construção do modelo foram aerofotos da cidade de Jataizinho da década de 1970 na escala de 1:25000, obtidas no Centro de Documentação e Pesquisa Histórica - CDPH, da Universidade Estadual de Londrina - UEL.

Para o georreferenciamento do par estereoscópico no software Prestitui.exe, utilizou-se um conjunto de coordenadas geodésicas coletadas através de técnicas GNSS. Destaca-se que outros dados foram utilizados para os devidos ajustes do modelo estereoscópico, tais quais: escala das aerofotos, altitude média do terreno das aerofotos, altura de voo na tomada das aerofotos, marcas fiduciais das aerofotos, distância focal calibrada e tipo de câmera utilizada para a obtenção das aerofotos.

A visualização estereoscópica foi realizada pelo modo anaglifo, fazendo-se uso de óculos tridimensionais. Os alvos vetorizados foram convertidos pelo próprio software para a extensão DXF, o que viabilizou a interoperabilidade dos dados vetoriais com softwares de geoprocessamento.

Para a etapa de interpolação dos pontos amostrais de altitude ortométrica do relevo, ao todo foram utilizados 610 pontos de elevação; o algoritmo utilizado para a interpolação foi o Topo to Raster, implementado no software ArcGIS. Ressalta-se que, devido a restrições técnicas, não foi possível realizar levantamento cinemático em campo para que se obtivesse maior quantidade de pontos de elevação do terreno in situ.

Os dados vetoriais e os dados interpolados foram sobrepostos ao mapeamento geomorfológico realizado por Sousa (2020) em escala 1: 25000 e, também, às imagens orbitais do satélite Rapideye, o qual possui resolução espacial de $5 \mathrm{~m}$, fato que possibilitou melhor análise visual da forma de ocupação da terra nas áreas sujeitas a inundação. As imagens orbitais foram adquiridas gratuitamente junto ao Geo Catálogo, um banco de imagens orbitais que é gerenciado por BRASIL (2014).

\section{Resultados e discussão.}

A interpolação dos dados altimétricos do terreno, obtidos por meio de estereoscopia digital igualmente feita para as formas de relevo, permitiu simular o transbordamento do Rio Tibagi sobre o sítio urbano de Jataizinho. Essa simulação foi feita até a maior cota altimétrica do Rio Tibagi já registrada pela estação fluviométrica de Jataizinho - 64507000, a saber, 342,02 m em 18/11/1937.

Por conseguinte, devido ao fato de o Rio Tibagi e os seus tributários que percorrem o sítio urbano de Jataizinho comporem um mesmo sistema, também foi possível visualizar a espacialização do transbordamento destes.

O intervalo dos dados interpolados foi estabelecido com base nas altitudes dos lances de régua da estação fluviométrica Jataizinho. Para isso, houve a necessidade de se calcular a altitude ortométrica da cota zero do primeiro lance de régua por meio de técnicas GNSS. Ao todo, a estação fluviométrica Jataizinho possui 5 lances de régua: $1^{0}$ lance entre $1 \mathrm{~m}$ e $3 \mathrm{~m}(335,02 \mathrm{~m}$ a $337,02 \mathrm{~m}) ; 2^{\circ}$ lance entre $3 \mathrm{~m}$ e $6 \mathrm{~m}(337,02 \mathrm{~m}$ a $340,02 \mathrm{~m}) ; 3^{\circ}$ lance entre $6 \mathrm{~m}$ a $7 \mathrm{~m}(339,02 \mathrm{~m}$ a $341,02 \mathrm{~m}) ; 4^{0}$ lance entre $7 \mathrm{~m}$ e $8 \mathrm{~m}(341,02 \mathrm{~m}$ a $342,02 \mathrm{~m})$; $5^{\circ}$ lance entre $8 \mathrm{~m}$ e $10 \mathrm{~m}(342,02 \mathrm{~m}$ a $344,02 \mathrm{~m})$.

A cota zero do primeiro lance de régua da estação fluviométrica Jataizinho - 64507000 foi calculada em 334,02 m; enquanto o nível de margens plenas foi obtido por meio de estereoscopia digital em 339,346 m. Desse modo, o nível de transbordamento do Rio Tibagi em relação à cota zero foi calculado em 5,326 m. A espacialização do transbordamento do Rio Tibagi e de seus tributários pode ser observada na (Figura 2).

A sobreposição dos dados interpolados ao mapeamento geomorfológico realizado por Sousa (2020), a saber, colina - Dc, planície fluvial - Apf e terraço - Atf, aponta que as áreas inundadas correspondem, principalmente, às planícies fluviais, sendo que parte significativa destas são ocupadas por habitantes da cidade. Em bem menor quantidade, as áreas inundadas correspondem a terraços. 


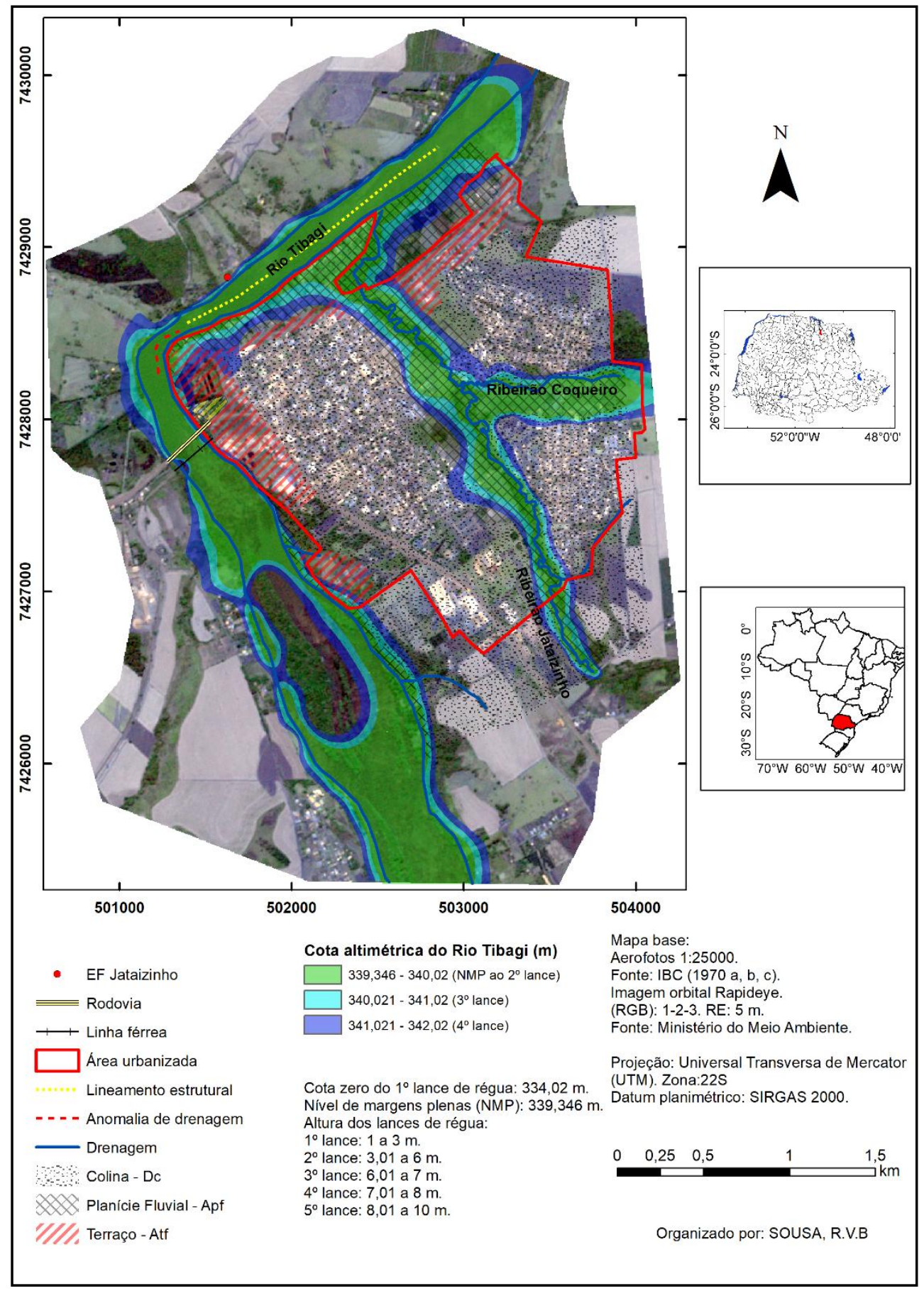

Figura 2: Espacialização das inundações na cidade de Jataizinho. Organizado por SOUSA, R.V.B.

É possível verificar que algumas poucas áreas de contato entre colina e terraço ou entre colina e planície apresentam-se como áreas inundadas. Esse fato ocorre devido a estas áreas de contato apresentarem pouca diferença na inclinação do relevo, o que fez com que, durante o processo de interpolação dos dados, elas fossem classificadas como áreas inundáveis. Tais áreas de contato, portanto, precisam ser analisadas com atenção, pois também se mostram vulneráveis a inundações.

Do ponto de vista quantitativo, as inundações estão concentradas em dois grupos principais, a saber, grupo A) inundações nas áreas de planície fluvial e na transição destas com áreas de terraço, compreendidas entre as cotas altimétricas $339,346 \mathrm{~m}$ e $340,520 \mathrm{~m}$ - do $2^{0}$ ao $3^{\circ}$ lance de régua da estação fluviométrica de Jataizinho -, e grupo B) inundações entre as áreas de terraço e na transição destas com algumas áreas de colinas, ou seja, entre as cotas altimétricas $340,521 \mathrm{~m}$ e $341,59 \mathrm{~m}$, cujo limite superior adotado foi o nível máximo já registrado pela estação fluviométrica Jataizinho, a saber, $342,02 \mathrm{~m}-$ do $3^{0}$ ao $4^{0}$ lance de régua da estação fluviométrica Jataizinho. As áreas afetadas por inundações, até o momento, estão compreendidas entre as cotas altimétricas do $2^{\circ}$ e do $4^{0}$ lance de régua da estação fluviométrica Jataizinho. 
Verifica-se que as inundações estão concentradas, principalmente, no grupo A. Não obstante, embora as inundações estejam concentradas em menor quantidade no grupo $\mathrm{B}$, estas correspondem às inundações mais bruscas.

A quantidade das inundações distribuídas nos diferentes grupos foi obtida levando-se em consideração os distintos períodos hidrológicos (PHs) do Rio Tibagi, calculados com base na técnica de Pettitt (1979), por Sousa (2017), de maneira que o autor identificou a existência de dois PHs, quais sejam, PH1, situado entre 1936 e 1970 - e PH2, situado entre 1971 e 2016. Nesse sentido, a quantidade de inundações nos diferentes grupos pode ser observada na (Tabela 1), na (Figura 3), na (Figura 4) e na (Figura 5).

Tabela 1: Total de dias de inundações do Rio Tibagi por períodos hidrológicos e pelos principais grupos.

\begin{tabular}{lcc}
\hline $\begin{array}{c}\text { Períodos Hidrológicos } \\
\text { (PH) }\end{array}$ & \multicolumn{2}{c}{ Quantidade de Inundações nos Diferentes Grupos } \\
& Grupo A (339,346 m a 340,520 m) & Grupo B (340,521 m $\geq)$ \\
\hline PH 1 (1936-1970) & 9 & 4 \\
PH 2 (1971-2016) & 30 & 6 \\
\hline
\end{tabular}

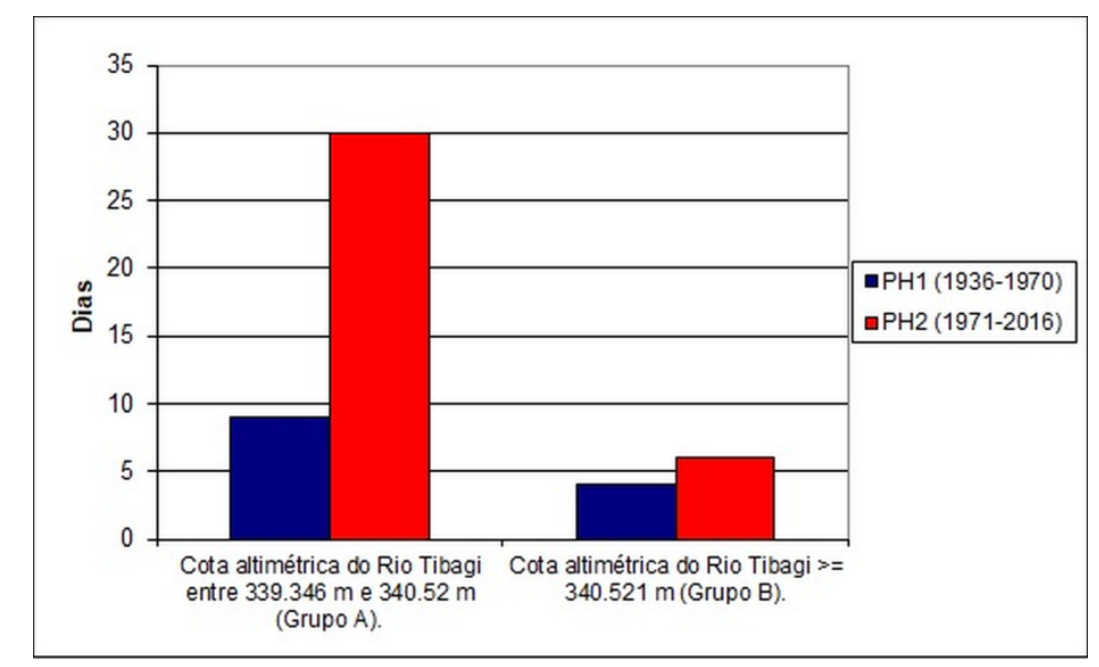

Figura 3: Total de dias de inundações por períodos hidrológicos e pelos principais grupos. PH: Período hidrológico. PH1 (1936-1970). PH2 (1971-2016). Organizado por SOUSA, R.V.B.

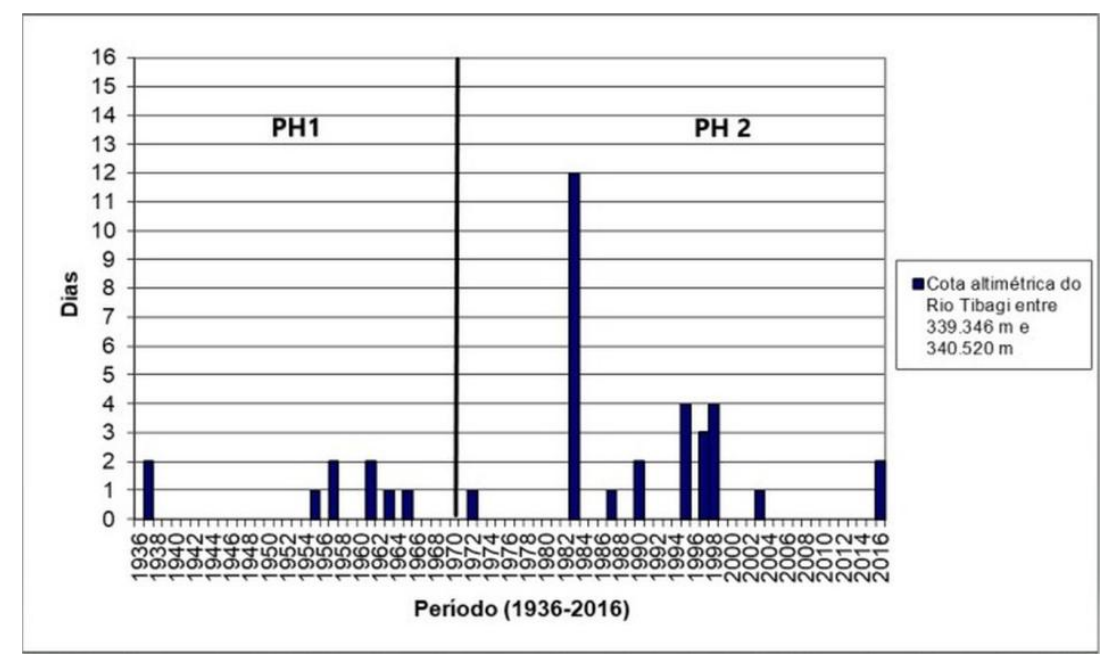

Figura 4: Total de dias de inundações interanual do Rio Tibagi referentes ao grupo A. PH: Período hidrológico. PH1 (1936-1970). PH2 (1971-2016). Organizado por SOUSA, R.V.B. 


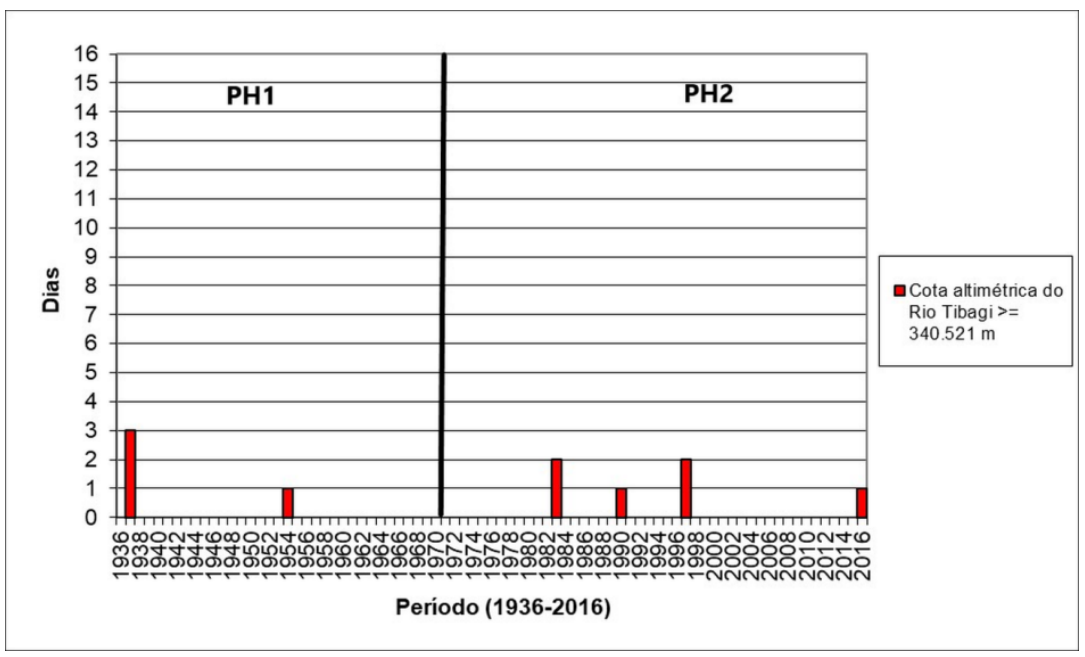

Figura 5: Total de dias de inundações interanual do Rio Tibagi referentes ao grupo B. PH: Período hidrológico. PH1 (1936-1970). PH2 (1971-2016). Organizado por SOUSA, R.V.B.

No cômputo geral, observa-se aumento de $233 \%$ nas inundações do grupo A e $50 \%$ nas inundações do grupo B, valores considerados altos. Embora não seja a intenção estabelecer uma relação de causa e efeito, é importante destacar que o PH1 e o PH2 coincidem, respectivamente, com os períodos hidrológicos pré e pós Usina Hidrelétrica de Capivara - UHE Capivara -, situada 118,23 km a jusante, no médio curso do Rio Paranapanema. Destaca-se, ainda, que, a estação fluviométrica Jataizinho - 64507000 -, encontra-se apenas 19,21 km a montante do limite máximo do remanso - Represa de Capivara -, no trecho que corresponde ao Rio Tibagi. Extensiva análise sobre essa problemática foi realizada por Sousa (2017), que não descarta que outras variáveis podem ter contribuído para a mudança de período hidrológico do Rio Tibagi, tais quais, mudança da cobertura da terra da Bacia Hidrográfica do Rio Tibagi e maior ocorrência de padrões de teleconexão global de alta frequência, como El Niño - Oscilação Sul (ENOS).

Com base nas cotas altimétricas máximas anuais do Rio Tibagi, calculou-se o período de retorno ou tempo de recorrência destas, para os dois períodos hidrológicos através da distribuição de Gumbel, descrito em Subramanya (2008). Considerações teóricas sobre a distribuição de Gumbel também são apresentadas por Tucci (2004) e Villela e Mattos (1975). Os tempos de recorrência e seus intervalos de confiança podem ser observados na (Figura 6), na (Figura 7) e na (Tabela 2).

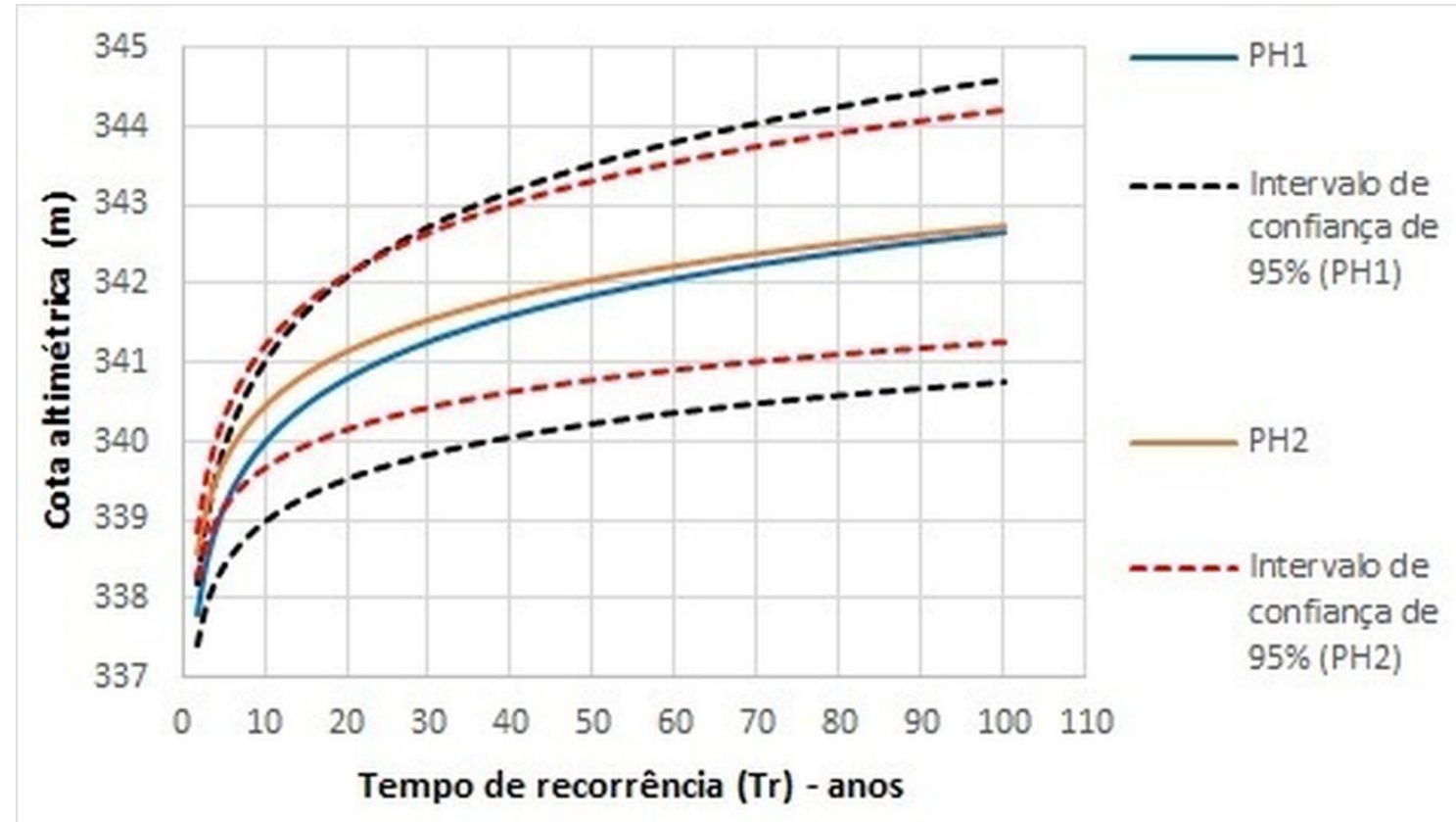

Figura 6: Tempo de recorrência (Tr) das cotas altimétricas máximas do Rio Tibagi - estação fluviométrica 64507000 - entre 2 e 100 anos. Organizado por SOUSA, R.V.B. 


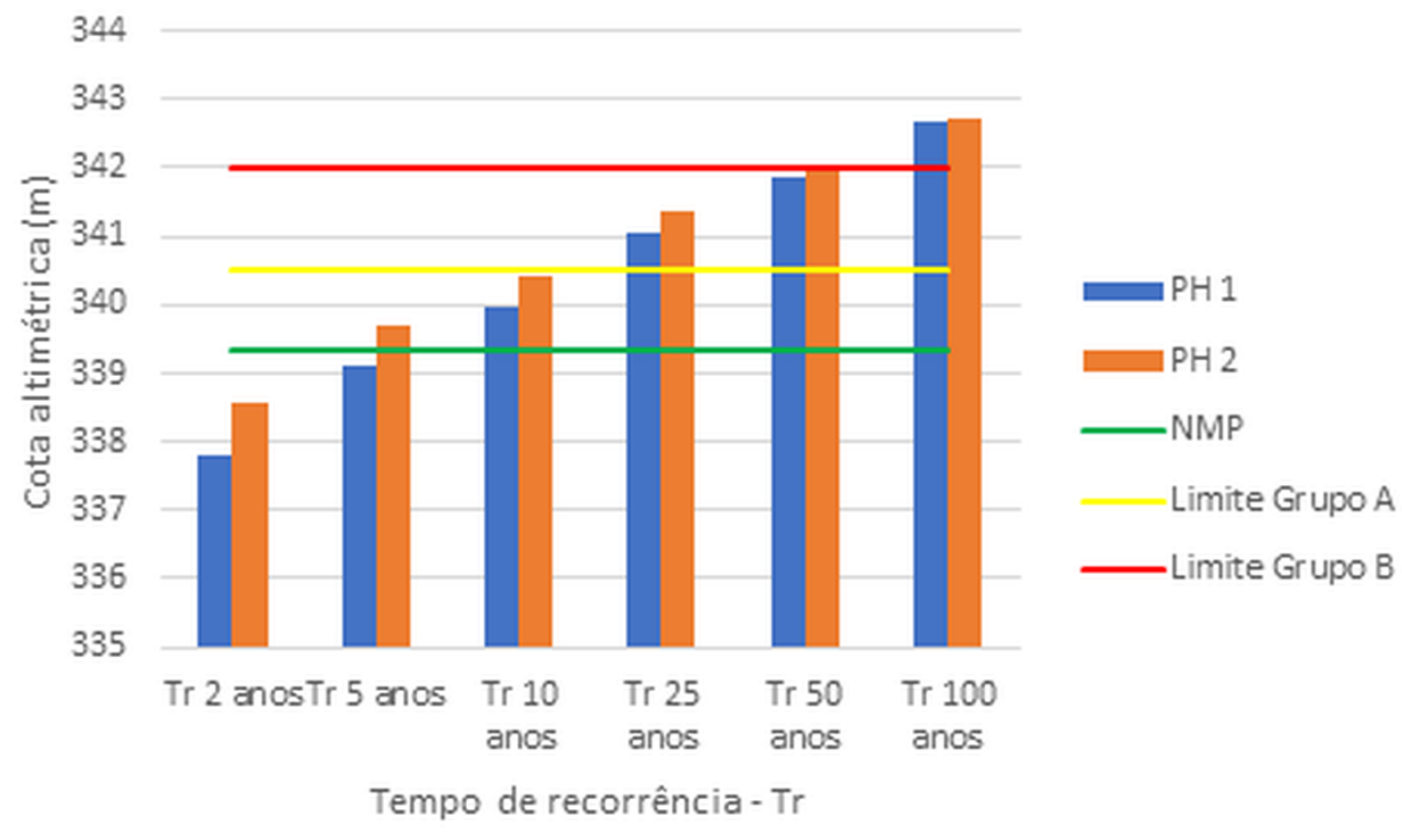

Figura 7: Tempo de recorrência (Tr) das cotas altimétricas máximas do Rio Tibagi - estação fluviométrica 64507000 - para 2, 5, 10, 25, 50 e 100 anos. NMP: Nível de margens plenas. Organizado por SOUSA, R.V.B.

Tabela 2: Tempo de recorrência (Tr) das cotas altimétricas máximas do Rio Tibagi - estação fluviométrica $64507000-$, para 2, 5, 10, 25, 50 e 100 anos.

\begin{tabular}{|c|c|c|c|c|c|c|}
\hline $\mathbf{P H}$ & $\operatorname{Tr} 2$ anos & $\operatorname{Tr} 5$ anos & Tr 10 anos & Tr 25 anos & Tr 50 anos & Tr 100 anos \\
\hline $\begin{array}{l}\text { PH1 (m) } \\
\text { Intervalo de confiança de } \\
95 \% \text { para PH1 (m) }\end{array}$ & $\begin{array}{l}337,803 \\
{[337,411 ;} \\
338,194]\end{array}$ & $\begin{array}{l}339,108 \\
{[338,374 ;} \\
339,841]\end{array}$ & $\begin{array}{c}339,972 \\
{[338,962} \\
340,981]\end{array}$ & $\begin{array}{l}341,063 \\
{[339,691 ;} \\
342,436]\end{array}$ & $\begin{array}{c}341,873 \\
{[340,227 ;} \\
343,520]\end{array}$ & $\begin{array}{c}342,677 \\
{[340,756 ;} \\
344,598]\end{array}$ \\
\hline $\begin{array}{l}\text { PH2 }(\mathbf{m}) \\
\text { Intervalo de confiança de } \\
95 \% \text { para PH2 (m) }\end{array}$ & $\begin{array}{l}338,565 \\
{[338,261 ;} \\
338,870]\end{array}$ & $\begin{array}{l}339,681 \\
{[339,114 ;} \\
340,249]\end{array}$ & $\begin{array}{l}340,420 \\
{[339,640 ;} \\
341,201]\end{array}$ & $\begin{array}{l}341,354 \\
{[340,294 ;} \\
342,415]\end{array}$ & $\begin{array}{l}342,047 \\
{[340,775 ;} \\
343,319]\end{array}$ & $\begin{array}{l}342,735 \\
{[341,251 ;} \\
344,219]\end{array}$ \\
\hline $\begin{array}{l}\text { Diferença da cota } \\
\text { altimétrica (PH2 - PH1) } \\
\text { (m) }\end{array}$ & $\uparrow 0,763$ & $\uparrow 0,574$ & $\uparrow 0,449$ & $\uparrow 0,291$ & $\uparrow 0,174$ & $\uparrow 0,057$ \\
\hline
\end{tabular}

Organizado por SOUSA, R.V.B.

Observa-se que as cotas altimétricas que dizem respeito ao transbordamento do Rio Tibagi, isto é, a partir do nível de margens plenas, possuem tempo de recorrência de 5 anos em diante. O PH2 denota as cotas altimétricas mais altas nos tempos de recorrência, tanto para as inundações do grupo A - áreas de planície fluvial e transição destas com áreas de terraço, compreendidas entre as cotas altimétricas 339,346 m e $340,520 \mathrm{~m}$ - quanto para as inundações do grupo B - áreas de terraço e transição destas com algumas colinas, compreendidas entre as cotas altimétricas $340,521 \mathrm{~m}$ e $341,59 \mathrm{~m}$, cujo limite superior adotado foi o nível máximo já registrado pela estação fluviométrica Jataizinho, a saber, 342,02 m. Entretanto, para as inundações do grupo B, ou seja, para os episódios mais extremos de inundações, o tempo de recorrência é a partir de 25 anos. As duas maiores diferenças altimétricas do nível do rio entre PH1 e PH2 dizem respeito aos tempos de recorrência de 5 anos e 10 anos, $0,574 \mathrm{~m}$ e 0,449 $\mathrm{m}$ respectivamente. Essa diferença diminui gradualmente em 0,291 m para Tr de 25 anos, $0,174 \mathrm{~m}$ para $\operatorname{Tr}$ de 50 anos e 5,7 cm para Tr de 100 anos. A cota de inundação para Tr de 100 anos mostrou-se superior à cota de inundação máxima já registrada pela estação fluviométrica Jataizinho, sendo, respectivamente, 0,657 m e 0,715 m para PH1 e PH2.

Sousa (2012) pontuou as áreas mais afetadas por inundações na cidade de Jataizinho. Ao cruzar essas informações com os resultados obtidos na presente pesquisa, é possível identificar três principais zonas afetadas por inundações. A descrição e a localização de cada uma destas zonas podem ser observadas na (Figura 8) e na (Tabela 3). 


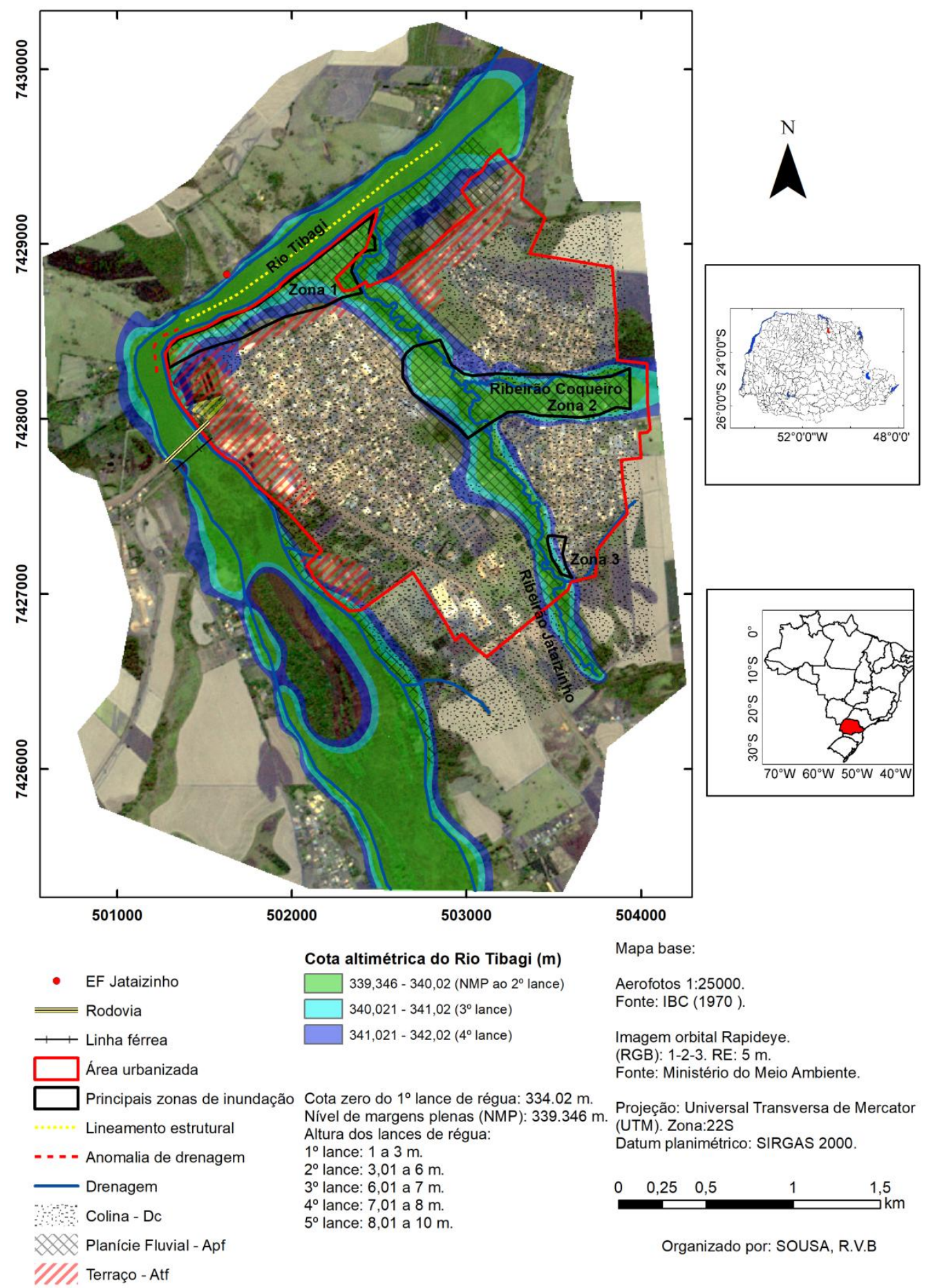

Figura 8. Identificação das principais zonas afetadas por inundações na cidade de Jataizinho. Organizado por SOUSA, R.V.B.

Tabela 3: Descrição dos locais inseridos em cada uma das principais áreas de inundação na cidade de Jataizinho.

\begin{tabular}{lll}
\hline \multicolumn{1}{c}{ Zona 1 } & \multicolumn{1}{c}{ Zona 2 } & \multicolumn{1}{c}{ Zona 3 } \\
\hline Área ocupada por chácaras. & Vila Frederico Lucarewiski, bairro pobre. Área & $\begin{array}{l}\text { Proximidades do conjunto Antonio } \\
\text { completamente inundada. }\end{array}$ \\
Associação dos servidora. \\
municipais & $\begin{array}{l}\text { Vila Bernardes, bairro pobre próximo à Vila } \\
\text { Frederico Lucarewiski. }\end{array}$ & \\
& Conjunto Milton Félix. Conforme informações de \\
& funcionários da prefeitura, já houve óbitos nesse \\
& local em decorrência de enchentes. & \\
\hline
\end{tabular}


Acerca das inundações que ocorrem em Jataizinho, Sousa (2012) assevera que existem duas situações no que concerne à ocorrência desses fenômenos:

A primeira diz respeito ao transbordamento natural do rio Tibagi para o leito maior, ocupado de forma irregular, principalmente por chácaras, nas quais residem, em grande maioria, famílias de classe média. A segunda ocorre dentro da área urbana, sendo a origem do fenômeno o remanso que o ribeirão Jataizinho, tributário do rio Tibagi, sofre em decorrência do aumento do nível deste (SOUSA, 2012, p.146).

O autor continua:

É na segunda situação em que os danos sociais e econômicos são mais contundentes, ocasionando perdas materiais para o município e para as famílias de bairros pobres como: o bairro Frederico Lukarewisk e Vila Bernardes. O último é considerado o ponto mais crítico, com ocorrência inclusive de óbitos. Conforme informações concedidas por funcionários da prefeitura de Jataizinho, o prejuízo causado à cidade em janeiro de 2010, em decorrência de inundações, superou o montante de um milhão de reais (SOUSA, 2012, p.146).

Nesse sentido, uma simulação de inundação até a cota altimétrica máxima do $5^{0}$ lance de régua da estação fluviométrica de Jataizinho, pode ser observada na (Figura 9); enquanto as áreas não inundadas, isto é, com altitudes acima do $5^{\circ}$ lance de régua, podem ser verificadas na (Figura 10).

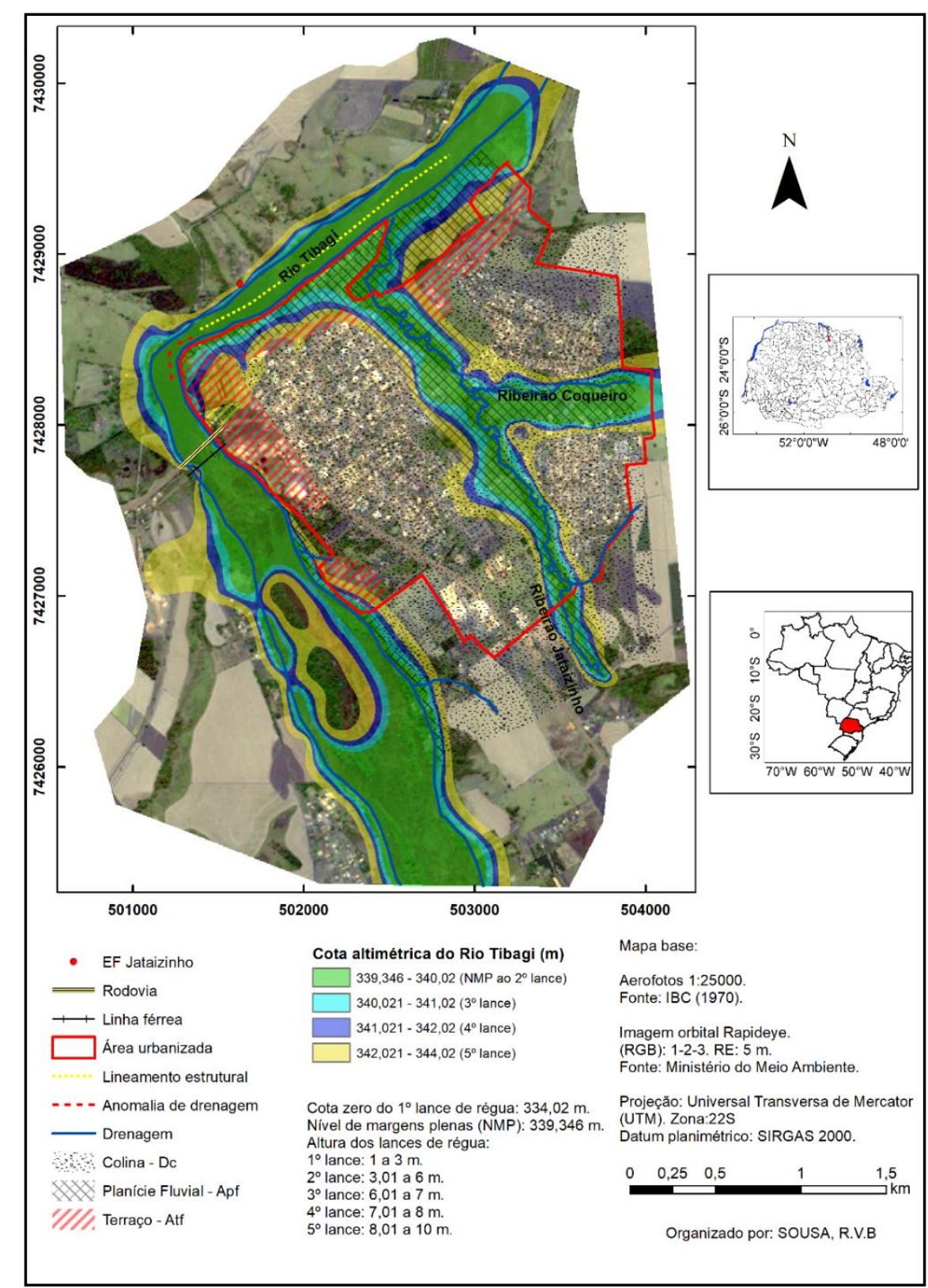

Figura 9: Simulação de inundação até a cota altimétrica do último lance de régua da estação fluviométrica. Organizado por SOUSA, R.V.B. 


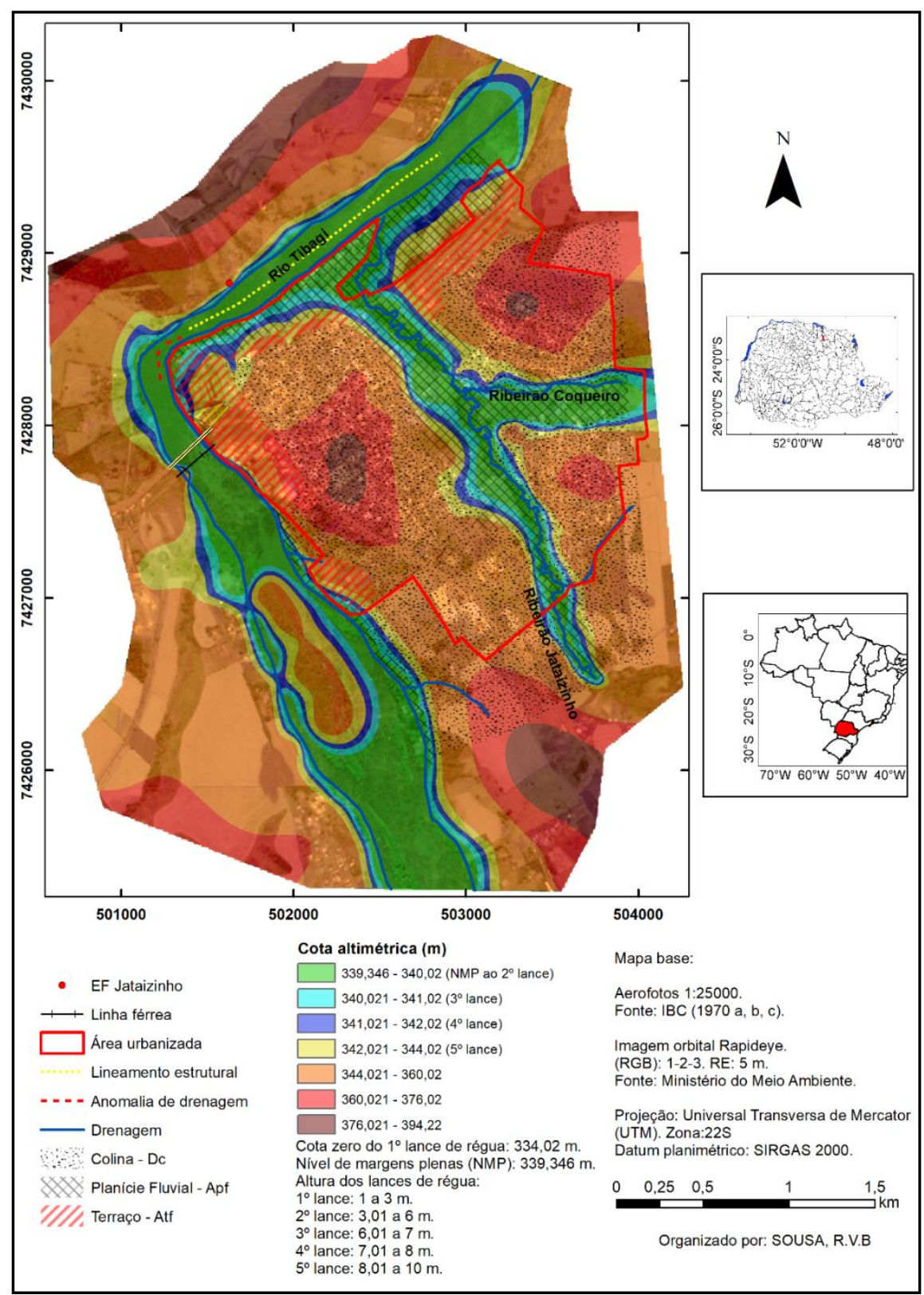

Figura 10: Representação da cota altimétrica do Rio Tibagi até o último lance de régua da estação fluviométrica e das áreas não inundadas. Organizado por SOUSA, R.V.B.

Analisando os dados de transbordamento do Rio Tibagi no trecho em que o rio é controlado pelo lineamento estrutural com direção SO-NE, próximo à anomalia de drenagem - cotovelo -, verifica-se que a inundação do canal fluvial ocorre principalmente na margem direita, local onde se encontra o sítio urbano de Jataizinho. Isso se deve à existência de inclinações mais baixas do relevo em relação à margem oposta, informação que está detalhada no mapeamento geomorfológico realizado por Sousa (2020).

\section{Considerações finais.}

A análise - que contemplou tanto as cotas altimétricas de transbordamento das drenagens quanto as formas de relevo mapeadas por meio de estereoscopia digital - apontou que as áreas inundadas correspondem, principalmente, às planícies fluviais - Apf. Em bem menor quantidade, as áreas inundadas correspondem a terraços - Atf e a áreas de transição destes com algumas colinas; situações que correspondem às inundações mais extremas. Os resultados obtidos permitiram analisar com maior segurança quais são as áreas sujeitas a inundação.

As cotas altimétricas de transbordamento das drenagens e as formas de relevo mapeadas - sobrepostas a imagens orbitais de alta resolução espacial - demonstraram que parte significativa das planícies fluviais e dos terraços é ocupada por habitantes da cidade. As cotas de inundação do Rio Tibagi apresentam-se mais altas para o tempo de recorrência do $\mathrm{PH} 2$, principalmente para o $\operatorname{Tr} 5$, com cota de 339,68 m, e para o $\operatorname{Tr} 10$, 
com cota de 340,420 m. Convém ainda destacar que as cotas altimétricas do Rio Tibagi referentes às inundações do grupo $\mathrm{B}$, os episódios mais extremos de inundação, possuem tempo de recorrência a partir de 25 anos.

A metodologia adotada mostrou-se satisfatória, na medida em que as cotas altimétricas de transbordamento das drenagens e do terreno obtidas por meio de técnicas GNSS, estereoscopia digital e técnicas de interpolação apresentam maior precisão altimétrica em comparação com os dados altimétricos extraídos dos Modelos Digitais de Elevação do SRTM ou TOPODATA.

Para pesquisas hidrológicas e geomorfológicas futuras, principalmente pesquisas relacionadas a inundações, podem ser utilizadas como base as altitudes ortométricas: a) do nível de margens plenas do Rio Tibagi, a saber: $339,346 \mathrm{~m}$, equivalente a $532,6 \mathrm{~cm}$ na régua linimétrica; b) da cota zero do primeiro lance de régua da estação fluviométrica Jataizinho - 64507000, qual seja, 334,020 m, dados obtidos por técnicas de estereoscopia digital e técnicas GNSS; c) do tempo de recorrência dos níveis máximos do Rio Tibagi.

Os resultados obtidos poderão ser utilizados como ferramenta de apoio ao ordenamento territorial e planejamento ambiental da cidade de Jataizinho, isso em conjunto com outros produtos cartográficos e planos de ordenamento territorial já desenvolvidos pela prefeitura da cidade. Recomenda-se, portanto, a inserção desses resultados no Plano Diretor do município.

\section{Agradecimentos.}

À Coordenação de Aperfeiçoamento de Pessoal de Nível Superior - CAPES, pelo aporte financeiro para o desenvolvimento desta pesquisa, que constituiu parte de Tese de Doutorado em Geografia pela Universidade Estadual Paulista - UNESP, Campus de Presidente Prudente.

\section{Referências}

AICARDI, I; BOCCARDO, P; CHIABRANDO, F; FACELLO, A; GNAVI, L; LINGUA, A; PASQUALE, F; MASCHIO, P; SPANOे, A. A didactic Project for landscape heritage mapping in post-disaster management. Applied Geomatics. v.7, n.1, p. 49-60. DOI: 10.11606/rdg.v38i1.158561.

ANA - Agência Nacional de Águas. HidroWeb: Sistema de Informações Hidrológicas. 2005. Disponível em: <http://hidroweb.ana.gov.br>. Acesso em: 01 out. 2017.

BRASIL. Ministério do Meio Ambiente. Geo Catálogo. 2014. Disponível em:<

http://geocatalogo.ibama.gov.br/>. Acesso em: 14/07/2014.

BRASIL. Ministério do Meio Ambiente; ANA - Agência Nacional Águas. Mapa de vulnerabilidade a inundações - Brasil. Brasília: ANA, 2015a. Disponível em: < http://www2.snirh.gov.br/home/webmap/viewer.html?webmap=cf201bd9b2c540fa951b0619006eb2af $>$.

Acesso em: 10 jul. 2015.

BRASIL. Ministério do Meio Ambiente; ANA - Agência Nacional Águas. Atlas de vulnerabilidade a inundações - Região Sul. Brasília: ANA, 2015b. Disponível em: < http://metadados.ana.gov.br/geonetwork/srv/pt/main.home>. Acesso em: 10 jul. 2015.

CHRISTOFOLETTI, A. Geomorfologia. 2. ed. São Paulo: Edgard Blücher, 1980, p. 1-105.

FRANÇA, V de. O rio Tibagi no contexto hidrogeográfico paranaense. In: MEDRI, M. E., et al. (Ed). A Bacia do Rio Tibagi. Londrina: 2002, p. 45-61.

HASEGAWA, J. K. Simulador digital do restituidor analógico: Orientação e restituição fotogramétrica digital baseada em técnicas analógicas. Presidente Prudente: FCT - UNESP, 2010, 60p.

IBGE - Instituto Brasileiro de Geografia e Estatística. Geodésia: Modelo de ondulação geoidal. MAPGEO 2010, versão 2015.2 Disponível em: http://www.ibge.gov.br/home/geociencias/geodesia/modelo geoidal.shtm>. Acesso em: 15/05/2015. 
LANE, S. N; JAMES, T. D; PRITCHARD, H. Photogrammetric and laser altimetric reconstruction of water levels for extreme flood event analysis. Photogrammetric Record. v. 18, n. 104, p. 293-307, 2003.

LUEDELING, E; SIEBERT, S; BUERKERT, A. Filling the voids in the SRTM elevation model - A TINbased delta surface approach. ISPRS Journal of Photogrammetry \& Remote Sensing, New York, v. 62, n. 4, p. 283-294, 2007. https://doi.org/10.1016/j.isprsjprs.2007.05.004.

MAACK, R. Geografia Física do Estado do Paraná. 2. ed. Rio de Janeiro: J. Olympio; Curitiba: Secretaria da Cultura e do Esporte do Governo do Estado do Paraná, 1981. p. 329-420.

MAIO, C. R. Interpretação de Imagens de Landsat na Bacia do Rio Araguaia. Revista Brasileira de Geografia, Rio de Janeiro, v. 42, n.1, p. 156-159, jan./mar., 1980.

MENDONÇA, F. de A. O Clima e o planejamento urbano de cidades de porte médio e pequeno: Proposição metodológica para estudo e sua aplicação à cidade de Londrina/PR, 1994. Tese (Doutorado em Geografia Física) - Universidade de São Paulo. Departamento de Geografia, São Paulo.

MENDONÇA, F. de A. Dinâmica atmosférica e tipos climáticos predominantes da bacia do rio Tibagi. In: MEDRI, Moacyr E., et al. (Ed.). A Bacia do Rio Tibagi. Londrina: 2002.

MOLINA, J; RODRÍGUEZ-GONZÁLVEZ, Pablo; MOLINA, M. C; González-Aguilera, Diego. Geomatic methods at service of water resources modelling. Journal of Hydrology, v. 509, p. 150-162, 2014.

MONICO, J. F. G. Posicionamento pelo GNSS: Descrição, fundamentos e aplicações. $2^{\text {a }}$ ed. São Paulo: Editora UNESP, 2008.

MONTEIRO, C. A. de F. Da necessidade de um caráter genético à classificação climática. Revista Geográfica. v. 31, n. 57, p. 29-44, 1962.

MONTEIRO, C. A. de F. Clima. In: INSTITUTO BRASILEIRO DE GEOGRAFIA E ESTATÍSTICA IBGE. Geografia do Brasil: Grande Região Sul. Rio de Janeiro: Divisão Cultural, Tomo I, 1968.

NEAL, J. C; BATES, P.D; FEWTRELL, T.J; HUNTER, N.M; WILSON, M.D; HORRITT, M.S. Distributed whole city water level measurements from the Carlisle 2005 urban flood event and comparison with hydraulic model simulations. Journal of Hydrology. v. 368, n. 1-4, p. 42-55, 2009.

NOVO, E. M. L. M; SANTOS, A. P. Monitoramento de enchentes através de sensoriamento remoto orbital: exemplo do Vale do Rio Doce. In: SIMPÓSIO BRASILEIRO DE SENSORIAMENTO REMOTO, 2. 1982, Brasília. Anais... São José dos Campos: INPE, 1982. p. 381-394. Disponível em: <http://urlib.net/dpi.inpe.br/marte@80/2008/09.30.13.02>. Acesso em: 20 set. 2018.

PETTITT A. N. A Non-Parametric Approach To The Change-Point Problem. Applied Statistics, 28, p. 126135, 1979.

PINTO, S. A; NOVO, E. M. L. M; PEREIRA, M. N. ROSA, R. Utilização de dados multitemporais do Landsat para a identificação de setores da planície fluvial sujeitos à inundação. Boletim de Geografia Teorética, Rio Claro, v. 15, n. 29/30, p. 182-195, 1985.

SOUSA, R. V. B. Estudo sobre as inundações no curso inferior do Rio Tibagi - PR, 2012a, 191pp. Dissertação (Mestrado em Geografia). Universidade Estadual de Londrina - UEL.

SOUSA, R. V. B; BARROS, M. V. F; PEREIRA NETO, O. C. Cálculo da área do espelho d'água, no curso inferior do rio Tibagi, através de operações aritméticas de bandas: Subsídio ao entendimento dos processos responsáveis pelas inundações, na cidade de Jataizinho - PR. Revista Brasileira de Geomorfologia, v.13, n.4, p.477-484, 2012.

SOUSA, R. V. B. Ocorrências de inundações no baixo curso do Rio Tibagi, município de Jataizinho PR: Variáveis determinantes, 2017, 449 pp. Tese (Doutorado em Geografia). Universidade Estadual Paulista "Júlio de Mesquita Filho", Faculdade de Ciências e Tecnologia - UNESP, Campus de Presidente Prudente. 
SOUSA, R. V. B; ROCHA, P. C; MOROZ-CACCIA GOUVEIA, I. C; HASEGAWA, J. K. Mapeamento geomorfológico do sítio urbano de Jataizinho, baixo curso do Rio Tibagi - PR. Revista Caminhos de Geografia. v.21, n.73, p.307-320, 2020. https://doi.org/10.14393/RCG217349324

SUBRAMANYA, K. Engineering hydrology. $3^{\text {a }}$ ed. Tata McGraw-Hil, New Delhi, 2008, 434 pp.

TUCCI, C. E. M. Hidrologia: Ciência e Aplicação. 3. ed. Porto Alegre: Editora UFRGS, 2004.

VALERIANO, M de M. Dados topográficos. In: FLORENZANO, T. G. (Org.). Geomorfologia: Conceitos e tecnologias atuais. São Paulo: Oficina de Textos, 2008.

VALERIANO, M. Modeling small watersheds in Brazilian Amazônia with SRTM-90m data. Computers \& Geosciences, Amsterdam, v. 32, n. 8, p. 1169-1181, 2006. https://doi.org/10.1016/j.cageo.2005.10.019

VALERIANO, M. Modelo digital de elevação com dados SRTM disponíveis para a América do Sul. São José dos Campos: INPE, INPE-10550-RPQ/756, 2004.

VÁZQUEZ, D; MENÉNDEZ, R; FERNÁNDEZ, E. Changes in fluvial sediments storage from aerial photograph analysis (river Narcea, Northern Cantabrian Range). Cuaternario y Geomorfología, v. 25, n. 34, p. 71-85, 2011.

VILLELA, S. M; MATTOS, A. Hidrologia aplicada. São Paulo: McGraw-Hill, 1975, 245 p.

ZAZO, S; MOLINA, J; RODRÍGUEZ-GONZÁLVEZ, P. Analysis of flood modeling through innovative geomatic methods. Journal of Hydrology. v. 524, p. 522-537, 2015. 